\title{
La alfabetización estética y la contribución de los museos como artefactos culturales
}

\author{
Gabriela E. Capelli \\ (Graduada de la Escuela de Ciencias de la Educación) \\ (Universidad Nacional de Rosario. Argentina)
}

\section{Resumen}

Transitando el siglo XXI la escuela es testigo de los avances de las nuevas tecnologías y de los medios de comunicación, la agudización de las desigualdades sociales, la entronización del presente, la globalización, el consumismo omnipresente, y un Estado y otras figuras de autoridad que se van desdibujando.

Ante estos fenómenos sociales que modifican la percepción y la construcción de las identidades de los sujetos, la escuela debe abrirse camino para generar nuevos espacios, y brindar herramientas cognitivas por medio de una transformación que responda a las necesidades de la época actual.

Vincular las nuevas tecnologías con la didáctica, entendiéndolas como un producto socio-cultural y no como mera herramienta para el aula, es un desafío que la escuela no debería dejar pasar.

Urge pensar nuevos espacios que contribuyan a constituir nuevas prácticas de alfabetización. Una manera posible sería la de establecer un vínculo con el arte de tal manera que la escuela presente la posibilidad de otorgar herramientas cognitivas para interpretar y producir mensajes además de acceder a nuevas formas de tecnología. Una de esas herramientas pueden ser los artefactos culturales, entre ellos los museos.

\section{Palabras clave:}

Alfabetización - Herramientas Cognitivas - Arte - Artefactos Culturales - Museos.

\section{Summary}

As XXI Century goes by, the school witnesses the advance of new technologies and communications media, sharpening of social inequality, browning of present time, globalization, omnipresent consumerism and an image of the State and other government authorities that are fading away.

At the sight of this social phenomena, that modifies the perception and the construction of new entities, the school must trace it's way to generate new spaces and offer knowledge tools to meet today's needs. 
To join new technologies with didactics, understanding them as a social and cultural product and not only as tools to be used at the class rooms, is a challenge that schools must face.

There is urgency to create new spaces to help setup new practices for alphabetization. One possible way would be to create a bond with art so that schools can provide cognitive tools to interpret and produce messages while having access to new technologies. Some of those tools could be cultural entities such as museums.

\section{Key words:}

Teaching - Alphabetization - Cognitive Tools - Art - Cultural Entities - Museums.

\section{Introducción}

La escuela lleva años alfabetizando, y para ello va moldeando sus prácticas a la medida de las necesidades de las contingencias sociales que la interpelan a ella y desde luego a todo el engranaje que funciona en derredor, desde el sistema educativo todo, hasta el currículum, los docentes y sus alumnos.

La temática de la alfabetización, más allá de los avatares, conjuga dos funciones asumidas por la escuela desde su aparición: la de ser un espacio de transmisión de la cultura y una marca de ciudadanía.

En la actualidad, la escuela conserva su razón de ser, pero se encuentra afectada -entre otras problemáticas- a la polisemia que el término alfabetizar fue adquiriendo con el correr del tiempo. Es muy común escuchar hablar de varios tipos de alfabetización que superan el término clásico tales como: alfabetización digital, mediática, ciudadana y otros para referir a la adquisición de saberes.

Si bien la institución escuela no debe estar ajena a estas cuestiones y mirarlas de soslayo, está claro que debe buscar modalidades diferentes a las que se viene practicando desde sus inicios, reformular esa forma de adquisición de saberes para hacer de la tarea de enseñar un acto de descubrimiento y apropiación acorde al contexto social en el que está inmersa. En estos términos alfabetizar habilita a hablar de otros lenguajes accediendo a nuevos códigos que permitan el acceso y uso creativo de los mismos.

La alfabetización estética puede ser pensada como una forma de acercar el lenguaje de las artes a la escuela de manera de contribuir a una forma de acercamiento al conocimiento diferente. Reconocer que el arte puede ser una herramienta de acceso a los saberes que circulan en la escuela de la mano de la contribución de los museos, es una propuesta posible. 
En tiempos en que las instituciones carecen de legitimidad -en comparación con los tiempos modernos- tanto las escuelas como los museos pueden pensarse como espacios privilegiados para propuestas innovadoras que den la posibilidad a los alumnos de pensar y de pensarse no sólo como consumidores sino como productores de objetos culturales. Para ello tanto las instituciones (museos - escuelas) como los agentes culturales (docentes - museólogos) pueden generar espacios de construcción de proyectos conjuntos que acerquen los productos culturales a los alumnos acorde a las necesidades específicas de cada contexto y les permitan significar "mundos posibles" que recreen sus posibilidades y amplíen sus horizontes.

Desde esta propuesta se entiende entonces que alfabetizar pasa a ser una forma de enseñar a leer otros soportes además de la lecto-escritura.

\section{La escuela ayer y hoy}

Guillermina Tiramonti -casi a modo de sentencia- enuncia "la escuela es una producción institucional de otro momento histórico y que, por lo tanto, nació asociada a otras circunstancias sociales, políticas, y culturales" (1).

La autora sostiene que la aparición de la escuela en la escena social data de los siglos XVII y XVIII acompañada por la conformación de los estados nacionales, los procesos de secularización del orden social, la conformación de la familia burguesa, y el desarrollo del capitalismo industrial

Ante esta tradición de matriz social estado-céntrica, se le antepone, en la actualidad, un proceso de globalización que rompe dicha matriz y en consecuencia despoja a la escuela de su potencialidad para instituir identidades.

En el actual contexto, tanto las culturas juveniles como los medios de comunicación y las nuevas tecnologías han presentado cambios que se traducen en distintos lenguajes que plantearon una ruptura ante los procesos socializadores homogeneizantes, nacionalistas con preeminencia de la cultura escrita produciéndose un desplazamiento hacia procesos diversificados, fragmentados, discontinuos con un fuerte potencial massmediático que conduce al consumo, al borramiento de fronteras de acceso al conocimiento y deja marcas claras en la geografía de los cuerpos y sus subjetividades.

Estos fenómenos rompieron el monopolio de la cultura escrita, la cual fuera representativa de la escuela de los tiempos modernos. Si bien la escritura aún sigue siendo un importante modo de representación, no es la única forma de acceder a nuevos significados y de esto la escuela debería tomar nota y emprender cambios y transformaciones en su propia gramática. 


\section{Los museos ayer y hoy}

Al igual que las escuelas, los museos se expandieron a partir del siglo XIX, en sintonía con los cambios epocales, articulándose con el entramado social, en particular con una idea de democratización y de acceso masivo a los bienes culturales de las mayorías.

Helena Alderoqui (2) historiza sus orígenes desde una actividad privada: el coleccionismo. La actividad de coleccionar estaba ligada a la clase dominante e iba determinando "la estética" condicionando desde su lugar todo lo atinente a la cultura. Los criterios de colección, a su vez, se iban modificando según el paradigma y su condicionamiento social, religioso, filosófico o económico que tocara en suerte. Los objetos coleccionados eran significados a partir de la valoración atribuida socialmente según los parámetros de unos pocos.

Sus inicios se remontan a la Antigüedad, con la colección de objetos con sentido religioso, cuando los faraones egipcios, bajo la concepción religiosa de creer en la vida más allá de la muerte, mandaban a construir cámaras mortuorias en las que depositaban sus riquezas más preciadas (Culto a la muerte).

La autora cita también a los griegos, que atribuían valor a las piezas artísticas a partir no sólo de su calidad sino también por la autoría del artista que lo había confeccionado (Culto al arte).

Los romanos consolidaron su poder imperial a partir de sus botines de guerra, conseguidos de la expropiación de bienes y riquezas de sus vencidos (Culto al poder militar).

En la Edad Media el cristianismo tomó a las iglesias como lugares de recolección por excelencia, teniendo los objetos una fuerte significación religiosa para no sólo cautivar la atención de los creyentes sino también enseñarles, ya que los objetos religiosos tenían finalidades didácticas y morales. Más tarde, la burguesía ascendente adquiere estas obras pero con la finalidad de coleccionarlas y hacerlas circular entre grupos minoritarios, ya que esta actividad otorgaba status social (al objeto, aún siendo religioso, se le atribuye otra connotación, esta vez de carácter social).

Durante el Renacimiento la estética se remite nuevamente al período clásico, carácter que pasan a adquirir las colecciones a las que tiene acceso un público restringido y poderoso económicamente.

Con el coleccionista del manierismo hicieron su aparición: "Las Cámaras de arte y de maravillas" que eran colecciones con un antecedente más universal, ya que las colecciones dejaron de ser sólo objetos de arte para pasar a ser objetos pertenecientes al mundo de las ciencias y la naturaleza. Se convierten más tarde en el antecedente de los museos de la actualidad. 
A mediados del siglo XVIII surge la idea de "patrimonio" como pertenencia de todos, lo que conlleva a exponer objetos en espacios tales como las galerías, también antecedentes de los museos, con la intención de exhibir las colecciones o donaciones que se recibían.

Atravesando el siglo XVIII y XIX, los museos pasan a ser como los conocemos hoy, espacios abiertos al público, con una fuerte preeminencia elitista al principio a causa de sus orígenes, de los que con el correr del tiempo se van transformando hasta llegar a ser pensados como espacios de comunicación abiertos a todos los ciudadanos.

Esta apertura conlleva a pensar el vínculo entre los objetos expuestos por el museo y los visitantes. Este replanteo da cabida a explorar propuestas que contemplen cierto tipo de interacción entre el público y los objetos o los mediadores que los significan: los guías, rompiendo con la concepción monolítica de los tiempos de la modernidad según la cual el vínculo era unidireccional: un sujeto portador de saber (guía o especialista por ejemplo) se dirigía a otro sujeto que iba a apreciar, observar, conocer y aprender (el público).

El uso de los espacios, tales como hacer visitas a ciertos sectores y no a todos, previo consenso entre docentes y guía, e incluso permitir parte del recorrido como espacio de búsqueda guiada con preguntas o pistas y no por el personal del museo, o la incursión de visitas con formatos lúdicos como hacer recorridos guiados con títeres o personajes relacionados a la temática convocante y el tipo de público, forman parte del replanteo.

En la actualidad parte de este replanteo de los museólogos y agentes relacionados, pasa por pensar estrategias de comunicación que contemplen situaciones de intercambio, que permitan a los visitantes hipotetizar y atribuir significados para luego sí confrontar con la visión de los especialistas o de la versión "oficial", es decir, la voz de los expertos. Desde esta perspectiva se apunta a un vínculo que fomente la interacción y el diálogo.

\section{Museos y escuelas: una alianza posible}

Las escuelas y los museos aparecen como fruto de tensiones sociales, ya que no son instituciones neutrales, pero también nacen como necesidad de hacer público aquello que había pertenecido al ámbito de lo privado: el acceso al conocimiento en el caso de las escuelas -la alfabetización como estandarte- y la posibilidad de tener acceso a objetos que portan historias y están cargados de significación -el patrimonio-, en el caso de los museos.

Tanto los museos como las escuelas pueden interactuar y beneficiarse mutuamente, al respecto es interesante la reflexión de Marta Dujovne (3) 
"para la escuela el museo debería ser una herramienta de acción en todo intento de mitigar brechas culturales. Y si el museo intenta ser una institución democratizadora tiene a la escuela como una intermediaria casi imprescindible, aquélla que le puede acercar públicos nuevos, que demasiado a menudo quedan afuera de los circuitos letrados".

Desde este lugar se puede pensar a las escuelas y a los museos como espacios potencialmente democratizadores en donde los educadores puedan concebir a los museos como herramientas para dar paso a un tipo de comunicación, un acercamiento a la apropiación simbólica de bienes culturales.

Para hacer posible esa apropiación simbólica se requiere de herramientas que posibiliten la interpretación. Concibiendo al museo como un espacio de comunicación o también como un texto a ser leído, le corresponde a la escuela otorgar dichas herramientas, en otras palabras, le corresponde alfabetizar...

La función alfabetizadora de la escuela

Emilia Ferreiro (4) plantea que la escritura comenzó siendo una marca de sabiduría. Saber escribir era una profesión, siendo ésta de privilegio ejercida por los "escribas", personas que manejaban la técnica de la escritura y que en cierto modo lo ejercían con arte, ya que los sistemas de escritura chino, sumerio, egipcio, etc. se plasmaban sobre diversos materiales tales como papiros, tablas de arcilla, tablillas de bambú, etc.

Jean Hèbrard (5), por su parte, plantea que la cultura que va a colocar a la escritura como marca de ciudadanía va a ser la griega. En la Antigua Grecia estar alfabetizado era condición ineludible para ser ciudadano. La Edad Media aportó lo que en la Edad Moderna constituyeron los saberes elementales: la enseñanza del latín dirigida a los clérigos y "las escuelas del ábaco" que enseñaban a contar a los comerciantes, más tarde serían traducidas como asignaturas que enseñaban a leer y escribir (hoy Lengua) y a contar (hoy Matemática). A su vez, a partir del siglo XIX se pasó de "formar al cristiano a formar al hombre como Hijo de la Patria" en medio de la aparición de los estados nacionalistas.

Llevando esta historización al plano de la escuela como institución, Hèrbrard considera que "la escuela fue instrumentada para la lectura", pasando por tres etapas: cuando en la Antigua Grecia estar alfabetizado era una condición de ciudadanía (dejó de ser un asunto de intelectuales como lo eran los escribas), cuando en el siglo XVI la Iglesia decide alfabetizar para formar al cristiano y una tercera etapa en la que las grandes naciones desplazan a la Iglesia y transforman a las escuelas en instituciones estatales 
a partir del siglo XIX. La escuela por entonces sostenía el mandato social de educar al ciudadano, la lectura formaba al hombre "culto".

Tanto Emilia Ferreiro como Jean Hérbrard, conciben a la actividad de leer y escribir como fruto de las redes sociales de cada época, por lo tanto la alfabetización es una construcción social, como lo son las instituciones encargadas de esta actividad.

En el siglo XIX estaba claro que a las escuelas se iba a aprender, siendo los textos escritos el soporte por excelencia. A los museos se iba a ver sin tocar, a escuchar a los especialistas y su lectura sobre el significado de los objetos exhibidos que a su vez eran considerados parte del patrimonio de cada país. Ambas instituciones legitimaban las formas de conocer, el acceso al conocimiento y a los bienes culturales, dando espacio a las respuestas más que a las preguntas, a las certezas más que a las dudas.

Hoy, a las puertas del siglo XXI, las certezas se van desvaneciendo, la confianza en las instituciones y en la palabra del hombre se debilita para abrir un campo fértil a la duda, a la relatividad y a otra percepción del paso del tiempo (más acelerada). Se plantean otras formas de acceder al conocimiento, se plantea por lo tanto otra forma de "alfabetizar".

La escuela de hoy no garantiza el gusto por la lectura o la escritura aunque los nuevos soportes tecnológicos sigan requiriendo de su práctica (el nuevo fenómeno del iletrismo acecha).

En la vida actual se requieren prácticas de lectura y escritura más complejas y en soportes diversos. Emilia Ferreiro plantea crudamente una realidad incontrastable cuando compara un mundo laboral cada vez más informatizado con una escuela cada vez más desactualizada y empobrecida.

Desde este lugar se entiende entonces que alfabetizar pasa a ser una forma de enseñar a leer otros soportes además de la lecto-escritura.

\section{Las alfabetizaciones del siglo XXI y la escuela}

A esta altura de los acontecimientos es importante tener en cuenta que la escuela tiene por delante el desafío de alfabetizar ciudadanos de cara al siglo XXI que estamos transitando otorgándole al término nuevos sentidos. Para ello, los docentes y todo el engranaje que se mueve en torno a ella debe tener en claro qué se entiende hoy por alfabetización.

En relación a las nuevas tecnologías aplicadas a la educación, Andrea Brito e Inés Dussel definen a la "alfabetización electrónica" así: "En el mundo anglosajón, hoy se habla de 'e-literacy' o alfabetización electrónica o digital para referirse a la educación que permite conformar una relación crítica, informada y productiva con las NTIC en una reflexión que abarca 
la enseñanza de la lectoescritura, las matemáticas, la informática y los medios (6), se señala que las nuevas prácticas de alfabetización hacen referencia a la capacidad de leer y escribir distintos tipos de textos, signos, artefactos, matices e imágenes a través de los cuales nos vinculamos y comprometemos con la sociedad en un sentido amplio" (7).

Entender la temática de la alfabetización en relación con la tecnología requiere entonces internarse en el término y explorar algunos de sus significados (recordemos que el término se ha tornado polisémico).

Sumado al concepto de alfabetización tradicional -enseñar a leer y escribir- se agrega el de alfabetizar sobre distintos portadores de textos o bien diferentes tipologías textuales que fueron corriendo de su lugar hegemónico a la letra impresa, tales como las imágenes traducidas en formatos como los video-clips, los textos sonorizados que circulan por Internet, etc. Ésta es una forma de alfabetización audiovisual.

Enseñar a leer los textos publicitarios, decodificar mensajes de programas televisivos o radiales, cuestionar mensajes emitidos por personas y personajes dentro de estos formatos sería una forma de pensar a la escuela como un "filtro cognitivo", es una forma de alfabetización mediática.

Pensarnos como lectores y escritores a la hora de contactarnos a Internet, hacer comprensible los mecanismos de lectura que vamos llevando a cabo para establecer enlaces y obtener información es una forma de alfabetización digital, que luego se traduce en el manejo de la telefonía celular móvil, o un cajero automático... (en este tipo de alfabetización en particular a veces la relación enseñante-educando se invierte...).

A través del tiempo la escuela fue testigo de revoluciones tales como la Revolución de la Imprenta y la Revolución Industrial, en cuyo encuadre fue dotando de sentido a la función alfabetizadora. Hoy tenemos ante nuestros ojos una nueva revolución, que se podría llamar Tecnológica o de las Comunicaciones tal vez, que requiere que esta función (alfabetizadora) sea resignificada.

El desafío pasa -en esencia- por que la escuela se convierta en un espacio disponible para otorgar al sujeto herramientas cognitivas que le permitan ser un ciudadano alfabetizado, productor de sentidos, partícipe activo, lector inteligente, constructor de significados, no sólo consumidores.

¿Cómo? Tal vez un camino posible sea, en las escuelas, el encuentro entre la Didáctica y las nuevas Tecnologías para crear herramientas o dispositivos al alcance de los alumnos que les ayuden a interpretar la realidad, a otorgarle significado a los símbolos que otorgan los lenguajes desde distintos soportes o artefactos culturales. 
El camino tiene que ser allanado por políticas educativas que ayuden a llevar a cabo el cambio, acompañado por la apertura de las instituciones involucradas (escuelas y museos), una flexibilización curricular y docentes que tomen el desafío de abordar la transmisión de algunos conocimientos desde otro lugar.

Una propuesta posible consiste en enseñar a leer artefactos culturales que no están al alcance directo de la escuela, pero con los cuales puedan propiciarse espacios de encuentro, tales como los museos. Entender a los museos -y los objetos que allí se exhiban- es una alternativa que ni las escuelas ni los museos deberían dejar pasar. Esto sería una forma de alfabetización estética.

Desde esta perspectiva la incorporación de algunas tecnologías interpeladas por el arte pueden transformarse en herramientas cognitivas que ayuden a comprender, a significar el mundo que nos rodea.

Lo interesante es que los docentes las acerquen a los alumnos no como una simple herramienta de trabajo o una figura decorativa innovadora. Lo relevante es su carácter social, su poder decodificador, su aporte para el acceso al conocimiento, su función alfabetizadora.

\section{La escuela y la alfabetización estética}

El arte suele tener un espacio secundario, subsidiario ante otros tipos de conocimiento. Redescubrir sus potencialidades para enriquecer otras áreas de conocimiento -no para desplazarlas sino para complementarlas y hasta enriquecerlas- es una alternativa posible. Una de esas potencialidades consiste en su impronta sensitiva, que abre espacio para la imaginación. La imaginación genera imágenes; estas imágenes suelen saturar nuestra percepción por la irrupción permanente a través de la televisión a la P.C. con un ritmo tan vertiginoso que no permite o no da tiempo a la interpretación, a la decodificación.

Traducir con palabras lo que las imágenes trasuntan o significan, confrontar ideas o interpretaciones, justificar las diferentes miradas en torno a una o a varias imágenes, lentificar el tiempo para dar conscientemente espacio a abrir otros sentidos además del de la vista, son habilidades cognitivas que la escuela puede llegar a ofrecer.

La escuela puede acercar a los chicos que concurren a ella a leer otros soportes textuales y que sean ellos los que otorguen significados. No es otra cosa que proponerles ser productor para dejar de ser meros consumidores.

La propuesta de enseñar a leer es alfabetizar... 


\section{La función alfabetizadora del arte (alfabetización estética)}

Elliot Eisner (8) plantea introducir en la enseñanza en las escuelas la sensibilidad que otorga el lenguaje del arte, tomando al arte como artefacto cultural. Desde esta concepción el arte aporta a los estudiantes una forma de acceder a la formación de los conceptos desde mecanismos heurísticos.

Para acercarnos al concepto de "artefactos culturales" Michael Cole (9) los presenta como productos de la historia humana que pueden ser ideales o materiales, tales como hachas o cuencos, hasta la imaginación plasmada en las obras de arte o en los procesos de percepción. Este autor plantea en su obra adoptar desde la Psicología cultural el término de "artefacto" para describir a la cultura como producto de la mediación entre éstos, los individuos y su entorno. Cole describe en su obra tres niveles de artefactos tomando la clasificación de Marx Wartofsky quien concibe:

I. Artefactos primarios: son los utilizados directamente en la producción (ej.: hachas, agujas, cuencos, etc. son ejemplos de Wartofsky, a los que Cole agrega: "palabras, instrumentos para escribir, redes de telecomunicaciones y personajes culturales míticos" dando idea que estos artefactos son el producto concreto, la "materia" transformada por la actividad humana.

II. Artefactos secundarios: son las representaciones de los primarios (creencias, recetas, tradiciones, normas, etc.) que cumplen el papel de preservar las creencias y tradiciones.

III. Artefactos terciarios: van más allá de su contexto de uso, pueden ser autónomos ya que pueden ser productos de la imaginación que ayudan a ver el "mundo real" (obras de arte y procesos de percepción son ejemplos de Wartofsky).

A partir de estos conceptos se hace palpable la relación que el entorno cultural establece con el hombre, sus actividades y productos. Si bien la institución escuela a la hora de enseñar privilegia el texto escrito, el lenguaje literal, como alternativa, Eisner invita a incorporar un lenguaje que promueva la comprensión desde la estética, en definitiva, presenta otra forma de conocer, otra forma de desarrollar formas de pensamiento. A esa forma de conocer le atribuye la capacidad de decodificar a partir de diferentes formas de representación convirtiendo al sujeto que tiene acceso a esa forma de conocer -desde un sentido metafórico- en un ser "multialfabetizado".

Eisner plantea que el lenguaje del arte cumple funciones cognitivas que podrían ser incorporadas a la escuela por los docentes. Sostiene que el arte cultiva la imaginación y que ésta genera imágenes que vemos con el ojo de la mente dando lugar a la representación. La representación es la 
estabilización de la idea o imagen en un material y posibilita que el sujeto dialogue con ella. Dicha representación a su vez se inscribe (inscripción) en una imagen o idea conservada que puede ser una pintura, un poema, etc.

Desde esta perspectiva se puede pensar un alumno que conceptualice a partir de representaciones no sólo por la vía de la cultura escrita, sino incorporando representaciones auditivas, visuales, sinestésicas... es decir, incorporando a su repertorio el aporte de otros lenguajes.

Considerando a la escuela como transmisora de cultura y a los docentes como repartidores de ocasiones, incluir el lenguaje del arte en la adquisición de conocimientos escolares es un desafío que la escuela puede tomar de la mano de otra institución ligada al área de la educación no formal como lo son los museos.

\section{Los museos y su contribución a la alfabetización estética}

Entendiendo a los museos como textos a ser leídos por los alumnos, una de las primeras tareas a llevar a cabo por parte de los docentes es la de derribar la idea de que los museos son sólo para "entendidos".

Así como Eisner planteaba que enseñar a leer con códigos no lingüísticos era una forma de equidad, de igual modo lo es crear lazos con una institución a la que se le suele atribuir cierto carácter elitista y que hoy podría contribuir a disminuir la brecha cultural. Si bien el museo es una institución abierta y democrática, la valoración en torno a ella suele quedar entrampada en un imaginario social que la torna de difícil acceso. Entonces las escuelas pueden ser intermediarias para lograr el acercamiento del público infantil y adolescente a los museos, y estos ser, a su vez, una herramienta de trabajo para las escuelas, un texto a ser develado. Para ello, una vez producido el encuentro, hay que crear espacios que puedan concretar la 0 las propuestas de manera sostenida en el tiempo y acordar metodologías de trabajo y enfoques, como por ejemplo la concepción de conocimiento, el intercambio entre alumnos, docentes y guías, etc.

Tanto las escuelas como los museos favorecen el acceso a la producción simbólica. Mariana Spravkin (10) plantea que el alumno debe convertirse en "usuario del museo" lo cual requiere un acto de apropiación. Para lograrlo, propone concebir al alumno (sujeto) como espectador activo. Entiende por espectador a un sujeto en condición activa de observar, mirar y así atribuir significados y aprehender la obra. A su vez, se dará a conocer el significado social que esa o esas obras u objetos tienen socialmente asignados, significados construidos por adultos o por el contexto cultural. 
Confrontar la propia construcción (construcción personal de cada niño o joven) y la socialmente asignada sería el cierre de ese proceso.

Este proceso es un diálogo entre los alumnos y los objetos exhibidos, a su vez, al hablarse de atribución de significados es un acto de leer, es alfabetizar. En propuestas como éstas, los alumnos acceden a espacios de construcción, espacios de producción en los que incorporan representaciones visuales en un ámbito diferente, al que no suelen tener acceso como sí lo puede ser la televisión o la P.C. (aunque ésta en menor escala). Aún así, la escuela debe tomar a estos formatos como aliados, no subestimarlos, ya que entrenan a los alumnos a través de sus propuestas en la cultura visual pero con la diferencia que no hay intercambio y si lo hay, tiende a la pasividad. Aquí, en este punto, rescato el poder educativo de ambas instituciones: escuelas y museos, espacios privilegiados para otorgar herramientas que permitan a los alumnos pensar por sí mismos, construir significados, construir la realidad... ser auténticos intérpretes.

\section{A modo de cierre}

Los cambios en la percepción del tiempo, la nueva cultura audio-visual, el avance de las nuevas tecnologías requieren un cambio en el estilo de pensamiento que incorpore nuevos códigos que impacten en la subjetividad de los alumnos y le otorguen herramientas de comprensión diferentes a las que se vienen dando hasta hoy.

Presentar a la escuela como decodificadora, como alternativa ante la pasividad y el consumismo al que suelen llevar los massmedia puede ser una propuesta atrayente. Más aún, proponer espacios individuales y/o colectivos que incorporen lenguajes que muchas veces quedan en segundo plano -como lo suele ser el lenguaje del arte- para acceder a conocimientos que por la vía tradicional suelen quedar en el olvido o sin dar, es un desafío a tener en cuenta.

Pensar en las nuevas alfabetizaciones abre un espectro de posibilidades para que la escuela se abra paso y le dé cabida. Hablar de alfabetizaciones es hablar de nuevos lenguajes y es a su vez hablar de códigos que nos abran la puerta para comprenderlos y hacer un uso creativo de ellos.

Hacer que el alumno pueda atribuir significados, confrontar con los significados que los objetos, lugares o hechos tienen asignados socialmente, ser intérprete, tener acceso a espacios culturales como los museos o espacios curriculares que inviten a más de una disciplina a pensar creativamente en torno a un concepto o problema, es hacer que ese sujeto (alumno) se sienta partícipe activo de la cultura, se sienta ciudadano, se sienta alfabetizado para comprender los lenguajes que lo circundan... 
En definitiva, los docentes nos tenemos que animar a generar procesos de pensamiento genuinos de la mano de la hipótesis, de la metáfora, herramientas que nos brinda el lenguaje del arte para luego provocar en los alumnos actos genuinos de aprendizaje, que les sirvan para decodificar la sociedad en la que viven, para estar insertos en la cultura.

"Recuerdo a una profesora, la Srta. Orcutt, que hizo esta afirmación en clase: 'Resulta muy curioso, no que el agua se congele a los $32^{\circ}$ Fahrenheit, sino que pase de un estado líquido a uno sólido'. Luego siguió dándonos una explicación intuitiva del movimiento browniano y de las moléculas, expresando un sentido de la maravilla igual, incluso mejor, que el sentido de maravilla que yo sentía a esa edad (alrededor de los diez años) por todas las cosas a las que dirigía mi atención, incluso asuntos como el de la luz de las estrellas extinguidas que sigue viajando hacia nosotros aunque su fuente ya se haya apagado. En efecto, ella me invitaba a ampliar mi mundo de maravilla para abarcar el de ella. No estaba tan solo dándome información. En cambio estaba negociando el mundo de la maravilla y la posibilidad. Las moléculas, los sólidos, los líquidos, el movimiento, no eran hechos; habían de usarse para reflexionar e imaginar. La Srta. Orcutt era la excepción. Era un acontecimiento humano, no un mecanismo de transmisión. No se trata de que mis otras maestras no marcaran sus actitudes. Se trata, en cambio, de que sus actitudes eran inútilmente informativas" (Bruner, 2004).

\section{Notas Bibliográficas}

(1) Tiramonti, G. (2005) La escuela en la encrucijada del cambio epocal, en Educaçao \& Sociedade, 26, (92), pp. 889-910, UNICAMP, Campinas.

(2) Alderoqui, H., "Colecciones privadas y patrimonios públicos", en Alderoqui, S. Museos y Escuelas: socios para educar. Buenos Aires, Paidós.

(3) Dujovne, M. (2006) "Algunas notas de lectura", Parte I, en Alderoqui, S. Museos y Escuelas: socios para educar. Buenos Aires, Paidós.

(4) Ferreyro, E. (2000) Conferencia Plenaria presentada en el $26^{\circ}$ Congreso de Editores de Buenos Aires. Trad. al inglés: "Reading and writing in a Changing World", en Publishing Research Quaterly, 16/3/2000, pp. 53-61.

(5) Hèrbrard, J. (2000) "El aprendizaje de la lectura en la escuela: discusiones y nuevas perspectivas", Conferencia dada e Biblioteca Nacional - Sala Cortázar, de la Ciudad de Buenos Aires.

(6) Lankshear \& Snyder, Teachers and Technoliteracy: Managing literacy, technology and learning in schools.

(7) Dussel, I. y Brito, A. (2002) "Perspectivas para otros encuentros entre escuela y nuevas tecnologías" Publicado en el sitio de Grupo Docente y la dirección es: http: //www.editorialoceano.cl. 
(8) Eisner, E. (2004) El arte y la creación de la mente. Barcelona, Paidós.

(9) Cole, M. Psicología Cultural - Una disciplina del pasado y del futuro, Cap. V Poner la cultura en el centro, Morata.

(10) Spravkin, M. (2006) "La construcción de la mirada. Cuando los chicos dialogan con el arte", en Alderoqui, S. Museos y Escuelas: socios para educar. Buenos Aires, Paidós.

\section{Referencias Bibliográficas}

- Alderoqui, S. (2006) Museos y escuelas: socios para educar. Buenos Aires, Paidós.

- Bruner, J. (2004) Realidad mental y mundos posibles. Barcelona, Gedisa.

- Noé, L. F. (2007) Noescritos - sobre eso que se llama arte. Buenos Aires, Adriana Hidalgo editora.

- $\quad$ Litwin, E. (2006) Tecnología educativa. Buenos. Aires, Paidós.

- Dussel, I. y Southwell, M. (2007) "La escuela y las nuevas alfabetizaciones Lenguajes en plural", en Revista El Monitor del Ministerio de Educación, Ciencia y Tecnología de la Nación, № 13, pp. 26-32.

- $\quad$ Brito, A. y Dussel, I. (2002) "Perspectivas para otros encuentros entre escuela y nuevas tecnologías", Publicado en el sitio de Grupo Docente y la dirección es: http://www.editorialocéano.cl. 